\title{
Malignant Pleural Mesothelioma: Treatment Options and Novel Therapies
}

\author{
Jeremiah T. Martin ${ }^{1}$, Brittany A. Zwischenberger ${ }^{1}$, Thomas Fabian ${ }^{2}$ \\ ${ }^{1}$ Department of Surgery, University of Kentucky, Lexington, USA; ${ }^{2}$ Section of Thoracic Surgery, Albany Medical Center, Albany, \\ USA. \\ Email: j.martin@uky.edu
}

Received November $14^{\text {th }}, 2013$; revised December $15^{\text {th }}, 2013$; accepted December $23^{\text {rd }}, 2013$

Copyright (C) 2014 Jeremiah T. Martin et al. This is an open access article distributed under the Creative Commons Attribution License, which permits unrestricted use, distribution, and reproduction in any medium, provided the original work is properly cited. In accordance of the Creative Commons Attribution License all Copyrights (C) 2014 are reserved for SCIRP and the owner of the intellectual property Jeremiah T. Martin et al. All Copyright (C) 2014 are guarded by law and by SCIRP as a guardian.

\begin{abstract}
Malignant pleural mesothelioma is a rare primary tumor rising from the pleura and is associated with exposure to asbestos fibers. Mesothelioma is a locally aggressive disease that usually presents at an advanced stage and has a median overall survival of 1 year. Treatment options rarely result in cure of disease and range from trimodality treatment, including chemotherapy, radiation, and surgery, to supportive care. In patients with limited local disease and good functional status, trimodality treatment with extra-pleural pneumonectomy, chemotherapy, and radiation is frequently employed. Best supportive care should be instituted for patients with metastatic disease and poor functional status. Palliative therapy focuses on control of pleural effusions with drainage techniques and pain with radiation therapy. Novel therapies are showing promise, including photodynamic therapy, immunotherapy, and molecular targeted therapy.
\end{abstract}

\section{KEYWORDS}

Mesothelioma; Asbestos; Pleura; Trimodality Treatment

\section{Introduction}

Malignant pleural mesothelioma (MPM) is a rare primary tumor rising from the pleura. It is associated strongly with exposure to asbestos and erionite fibers, which were widely used in construction prior to the 1970s. Only 5\% of exposed patients will proceed to develop the malignancy. However, the long latency period of 20 - 40 years prior to the development of the disease explains the recent steady increase in incidence of new cases. This currently represents about 3000 new cases per year in the US, [1] and corresponds to the peak use of asbestos in the last century [2-4]. In 1989, the US Environmental Protection Agency banned most asbestos-containing products. The incidence of mesothelioma in the US is now leveling off while its incidence is increasing in some other countries. Mesothelioma is histologically classified into four groups: epithelioid, sarcomatoid, mixed, and desmoplastic [5]. Of these, the epithelioid variant has the best outcome, although this is only in relative terms. The median survival of a patient diagnosed with mesothelioma is reported in various databases from 8 to 13 months [6-8].

\section{Current Practice \& Controversy}

Patients with MPM frequently present with shortness of breath and associated pleural effusion. Mesothelioma is a locally aggressive disease; first presenting in one hemithorax, it progresses by traversing the diaphragm to involve the peritoneum, extending into the pericardium, and ultimately metastasizes systemically [9]. Workup and diagnosis should include biopsy for tissue confirmation of histologic subtype, which is best obtained by thoracoscopy. Any invasive procedure should be planned such that port sites may be excised at the time of thoracotomy. Current consensus guidelines from the International Mesothelioma Interest Group recommend complete pre-treatment staging, including surgical sampling of mediastinal lymph nodes, CT and/or PET scan, and MRI [10]. 


\section{Overview of Treatment Options}

Today's accepted treatment options for patients suffering from MPM range from best supportive measure to trimodality treatment (TMT) including surgical resection with extrapleural pneumonectomy (EPP). Within this spectrum are the full range of options for palliation, including chemotherapy, radiotherapy, and surgery (other than EPP). As with virtually all other malignancies, these choices are determined by tumor stage, patient's functional status, and patient desires. In patients with limited local disease and good functional status, TMT with EPP, chemotherapy, and radiation is frequently employed.

Best supportive care should be instituted for patients with metastatic disease and poor functional status. The majority of their care is focused on control of symptoms and emotional support. Control of pleural effusions resulting in dyspnea is critical to palliate the patient. Talc pleurodesis maybe appropriate and can be performed at the time of thoracoscopic diagnosis. Alternatives include bedside talc or chemical pleurodesis via thoracostomy tube. In scenarios where the lung is trapped, tunneled pleural catheters can be considered to control the effusion and provide symptomatic relief [11]. For patients with pain as a primary symptom, radiotherapy can be delivered; however, pain control is frequently limited secondary to tumor progression and additional disease sites [12].

Patients with a satisfactory functional status who undergo palliative chemotherapy were shown to have a prolonged survival. This approach is appropriate for patients who either choose non-radical therapy or are not candidates for a more aggressive strategy secondary to comorbidities or advanced stage tumor. Chemotherapy is also indicated as a single modality in patients with sarcomatoidhistology. The evidence supporting combinations of cisplatin and premetrexed/raltitrexed demonstrate improved survival and preservation of pulmonary function compared to cisplatin alone [13]. There are chemotherapy agents that can also be used as second-line therapy including pemetrexed (if not used first line), vinorelbine, and gemcitabine. However, when patients fail to respond, second-line therapy is often not recommended unless in the context of a clinical trial.

Primary radiation therapy has been employed for the treatment of mesothelioma alone. It is not presently recommended by any oncologic societies secondary to complications of non-target organs [14]. Side effects of hemi-thoracic radiation are not well tolerated and morbidity from this treatment precludes its use.

Palliative surgery typically includes treatment of entrapped lung for symptom palliation or total pleurectomy for local control. Most would argue against palliative surgery for entrapped lung secondary to high morbidity and poor long-term outcomes, particularly when alternative treatments, including the PleurX catheter (CareFusion), are available. Total pleurectomy, also known as pleurectomy/decortication (P/D), has been used with success to palliate symptoms. Further discussion of surgical options and the surrounding debates is detailed below.

Consensus guidelines have been published in recent years from organizations worldwide such as the National Comprehensive Cancer Network (NCCN) in the United States [15], the British Thoracic Society (BTS) [16], and the European Society of Medical Oncology (ESMO) [17]. For the purposes of this review, major society guidelines published within the past five years are examined, and a comparison is reported in Table 1.

We now examine some of the important clinical trials that have been used to guide contemporary practice.

\subsection{Induction Therapy/Chemotherapy}

The current standard of care for induction therapy in mesothelioma is the combination of a platinum-based agent such as cisplatin or carboplatin with an antifolate such as pemetrexed. Vogelzang conducted a phase III trial which demonstrated that this combination was associated with an overall response rate of $41.3 \%$ when compared with cisplatin alone. Overall survival was improved from 9.3 months to 12.1 months [13]. When comparing carboplatin to cisplatin, the latter is more commonly associated with neutropenia whereas carboplatin is more likely to cause anemia and thrombocytopenia. Outcomes are otherwise similar suggesting that these therapies may be substituted depending on the particular clinical situation [18].

In those patients whose performance status and comorbidities make them ineligible to undergo a surgical resection, the role of palliative chemotherapy has been evaluated. This question is challenging, and the data from a resulting phase III trial of active symptom control (ASC) versus ASC plus chemotherapy are not clear. Unfortunately, slow accrual and changes to trial design did not allow the primary endpoint to be analyzed; however, this study did demonstrate that overall survival is in the order of 7 - 8 months for those patients who elect not to undergo chemotherapy [19].

A major challenge in the management of mesothelioma is determination of treatment response. The Response Evaluation Criteria in Solid Tumors (RECIST) tool uses radiographic criteria to determine response or progression however a modification of this, which is based on CT dimensions of pleural thickness, is gaining traction as a means of standardizing this assessment $[20,21]$.

\subsection{Cytoreductive Surgery}

Extraplerualpneumonectomy was first described in the context of multimodality therapy in the 1970s [22]. As a locally aggressive disease, it has been generally felt that 
Table 1. Summary of current international society and consensus guidelines on the management of malignant pleural mesothelioma.

\begin{tabular}{|c|c|c|c|c|}
\hline Guideline & $\begin{array}{c}\text { National comprehensive } \\
\text { cancer network (NCCN) v } \\
1.2014[15]\end{array}$ & $\begin{array}{c}\text { British thoracic society } \\
\text { standards of care } \\
\text { committee [16] }\end{array}$ & $\begin{array}{l}\text { European respiratory society/ } \\
\text { european society of thoracic } \\
\text { surgeons task force[14] }\end{array}$ & $\begin{array}{c}\text { European society of medical } \\
\text { oncology guidelines } \\
\text { working group[17] }\end{array}$ \\
\hline Date Issued/Updated & $8 / 12 / 2013$ & $8 / 13 / 2007$ & $8 / 28 / 2009$ & $3 / 2010$ \\
\hline Initial evaluation & $\begin{array}{l}\text { CT chest/abdomen } \\
\text { Thoracentesis Pleural biopsy } \\
\text { Multidisciplinary management } \\
\text { PFT, PET, mediastinoscopy } \\
\text { for clinical stage I-III and } \\
\text { non-sarcomatoid histology. }\end{array}$ & $\begin{array}{l}\text { Multidisciplinary evaluation } \\
\text { CT or US-guided } \\
\text { tissue biopsy } \\
\text { If diagnosis uncertain, } \\
\text { follow with interval } \\
\text { imaging. Otherwise refer to } \\
\text { specialist mesothelioma } \\
\text { multidisciplinary team. }\end{array}$ & $\begin{array}{l}\text { Chest CT is suggestive but not } \\
\text { diagnostic. (1A) MRI is not } \\
\text { relevant for diagnosis (1B). } \\
\text { PET scanning is not } \\
\text { useful in the } \\
\text { initial evaluation (1C). } \\
\text { Thoracoscopy is the best } \\
\text { diagnostic tool and should be } \\
\text { performed for diagnosis (1A). }\end{array}$ & $\begin{array}{l}\text { Clinical staging is based on } \\
\text { CT scan of the chest, } \\
\text { pleuroscopy or thoracoscopy } \\
\text { is required for tissue } \\
\text { diagnosis and histologic } \\
\text { confirmation. }\end{array}$ \\
\hline Supportive Therapy & $\begin{array}{l}\text { For inoperable patients, talc } \\
\text { pleurodesis or pleural } \\
\text { catheter is recommended for } \\
\text { management of effusion. } \\
\text { Smoking cessation, pain } \\
\text { management, anti-emesis and } \\
\text { palliative guidelines are } \\
\text { referenced. }\end{array}$ & $\begin{array}{l}\text { Early pleurodesis is a key } \\
\text { aim for symptom control. } \\
\text { Talc is the recommended } \\
\text { agent of choice. } \\
\text { Thoracoscopy is a useful } \\
\text { diagnostic and } \\
\text { thereapeutic tool. }\end{array}$ & $\begin{array}{l}\text { Early pleurodesis should be } \\
\text { performed (1C) and sterile talc } \\
\text { is preferred (1A). Pain may be } \\
\text { managed via general principles } \\
\text { but involvement of a pain } \\
\text { specialist should be } \\
\text { considered (1C). }\end{array}$ & $\begin{array}{l}\text { Local surgical procedures } \\
\text { such as partial pleurectomy } \\
\text { and pleurodesis are } \\
\text { recommended. }\end{array}$ \\
\hline Surgical management & $\begin{array}{l}\text { Surgical exploration either as } \\
\text { primary therapy, or after } \\
\text { cisplatin/pemetrexed } \\
\text { induction followed by } \\
\text { restaging imaging. If } \\
\text { resectable, P/D or EPP should } \\
\text { be performed by thoracic } \\
\text { surgeon with experience in } \\
\text { management of MPM. Goal of } \\
\text { surgery is complete gross } \\
\text { cytoreduction. } 3 \text { nodal stations } \\
\text { should be sampled. }\end{array}$ & $\begin{array}{l}\text { Radical surgery (EPP) } \\
\text { should only be considered in } \\
\text { the context of a clinical trial. } \\
\text { Surgery should be } \\
\text { concentrated in centers of } \\
\text { experience. Surgery should } \\
\text { be performed in the context } \\
\text { of multimodality therapy. }\end{array}$ & $\begin{array}{l}\text { P/D does not offer chance of } \\
\text { cure, but should be offered for } \\
\text { symptom control (2C). VATS } \\
\text { approach is preferred (1C). } \\
\text { Radical surgery (EPP) should } \\
\text { only be performed in } \\
\text { specialized centers, as part of } \\
\text { clinical trials, as a component } \\
\text { of multimodality therapy. }\end{array}$ & $\begin{array}{l}\text { Surgery should only be } \\
\text { performed by experienced } \\
\text { centers, and as part of a } \\
\text { clinical trial. }\end{array}$ \\
\hline Chemotherapy & $\begin{array}{l}\text { First-line combination } \\
\text { regimens for induction therapy } \\
\text { or for palliative control: } \\
\text { Pemetrexed, Cisplatin } \\
\text { Pemetrexed, Carboplatin } \\
\text { Gemcitabine, Cisplatin } \\
\text { Pemetrexed Vinorelbine. }\end{array}$ & $\begin{array}{l}\text { Several agents have shown } \\
\text { to be helpful. Clinical trials } \\
\text { should be encouraged. } \\
\text { Pemetrexed-cisplatin is } \\
\text { recommended as a first-line } \\
\text { agent given improved } \\
\text { survival versus } \\
\text { cicplatin alone. }\end{array}$ & $\begin{array}{l}\text { Every patient should receive } \\
\text { best supportive care at a } \\
\text { minimum (1A). First-line } \\
\text { platinum with pemetrexed or } \\
\text { ralitrexed (1B). Alternatively } \\
\text { include in first-line clinical } \\
\text { trials. Treatment should not be } \\
\text { delayed (1C). }\end{array}$ & $\begin{array}{l}\text { Pemetrexed/Cisplatin, and } \\
\text { ralitrexed/cisplatin are } \\
\text { favored due to available data. } \\
\text { Platinum based induction or } \\
\text { adjuvant chemotherapy } \\
\text { should be used in the setting } \\
\text { of surgical management. }\end{array}$ \\
\hline Radiation Therapy & $\begin{array}{l}\text { Evaluation by radiation } \\
\text { oncologist as part of a } \\
\text { multidisciplinary team. RT is } \\
\text { effective for both local control } \\
\text { and symptom control in the } \\
\text { palliative setting. It should be } \\
\text { considered to prevent } \\
\text { instrument-tract recurrence } \\
\text { after pleural intervention even } \\
\text { in the palliative setting. } \\
\text { Dosimetry should be tailored } \\
\text { but as a general rule should } \\
\text { include the entire hemithorax, } \\
\text { incisions and drain sites. } 54 \mathrm{~Gy} \\
\text { as first-line therapy. Doses } \\
\text { over 60Gy may be considered } \\
\text { for residual tumor. }\end{array}$ & $\begin{array}{l}\text { Radiation plays an important } \\
\text { role in the multidisciplinary } \\
\text { management. Pain relief has } \\
\text { been shown in half of } \\
\text { patients, and radiation } \\
\text { should also be considered } \\
\text { for local complications such } \\
\text { as SVC sundrome. } \\
\text { Prophylactic radiotherapy } \\
\text { should be used in patients } \\
\text { with good performance } \\
\text { status after invasive pleural } \\
\text { procedures to reduce chest } \\
\text { wall implantation. }\end{array}$ & $\begin{array}{l}\text { No definitive recommendation } \\
\text { for prophylactic RT due to } \\
\text { conflicting data. RT should not } \\
\text { be performed after P/D (1A), } \\
\text { RT should be performed after } \\
\text { EPP in specialized centers, as } \\
\text { part of clinical trials, as a } \\
\text { component of multimodality } \\
\text { therapy (1A). }\end{array}$ & $\begin{array}{l}\text { The role of definitiveRT is } \\
\text { unclear; however, radiation } \\
\text { has a role in palliation of } \\
\text { pain and for prevention of } \\
\text { obstructive symptoms. RT } \\
\text { may be considered to } \\
\text { improve local control } \\
\text { after EPP. }\end{array}$ \\
\hline
\end{tabular}

a procedure to remove all visible and palpable disease should afford the best outcomes. One of the many chal- lenges faced by clinicians and researchers is the wide practice variation in the surgical treatment of mesothe- 
lioma [23]. However, in those centers with experience in the surgical management of mesothelioma, cytoreductive surgery plays an integral role as a component of TMT, especially in the context of clinical investigation [24].

The most aggressive approach is extrapleural pneumonectomy (EPP) which removes all of the lung parenchyma on the affected side, in addition to both visceral and parietal pleura, the pericardium, and diaphragm. Patch reconstruction of the diaphragm and pericardium is then undertaken. The advantage of this approach is the relative ease by which radiation therapy may be delivered to the ipsilateral hemithorax without concern for irradiating a lung.

The alternative surgical approach involves a procedure directed mainly at the pleura and malignant disease. The term pleurectomy and decortication is widely used in the literature; however, its precise application varies widely. Recently, calls for standardization of nomenclature have been made to facilitate future study and accurate followup [23]. Extended pleurectomy/decortication (EPD) involves removal of all of the parietal and visceral pleura and resection of the diaphragm and/or pericardium when involved with tumor. Pleurectomy/decortication (P/D) involves removal of pleural surfaces without removal of the diaphragm or pericardial resection. Finally, partial pleurectomy is a palliative or diagnostic procedure with known tumor left behind.

Although surgery has always held an important role in the overall treatment of mesothelioma, the available literature is conflicting and the debate continues. Attempts were made to establish a randomized control trial to answer this important question. The Mesothelioma and Radical Surgery (MARS) trial was designed to evaluate patients in a chemotherapy plus surgery arm versus a chemotherapy only arm. The initial trial, MARS I, was published after evaluating 50 patients [25]. This design of this trial was held in high regard and with expectations of helpful data to further management decisions. As a feasibility trial it was hoped to continue the study. However these early results were not promising, and a more extensive study under the MARS guidelines was not possible. These outcomes have fueled the debate over surgery further with proponents on both sides. Several important and very limiting issues were identified upon examining the MARS I trial [10]. In particular, not all patients in the surgery arm actually underwent a definitive operation, and 3 patients in the chemotherapy only arm underwent surgery outside the study protocol. Additionally, morbidity and mortality was higher than the reported literature, and chemotherapy use was not controlled. As such, this question has not been adequately addressed and requires further study. Nonetheless, the current recommendation of the International Mesothelioma Interest Group (IMIG) is that surgery should con- tinue to play an important role when macroscopic complete resection is deemed achievable [10].

\subsection{Radiation Therapy}

As the final component of TMT, radiation therapy is accepted as standard of care. Mesothelioma is felt to be poorly radiosensitive; however, in vivo results favor the use of directed therapy. In addition, modern techniques of radiation delivery, including intensity modulated radiation therapy (IMRT), allow for minimization of local and systemic toxicity. In general, radiation is well tolerated after EPP as the ipsilateral hemithorax, devoid of lung tissue, can tolerate high-dose therapy. Reports of conventional radiation after surgery demonstrate high rates of local control. In 2001, Rusch and colleagues reported the results of a phase II trial of surgery and highdose hemithoracic radiation. There were two locoregional failures in 54 patients and median survival was 17 months overall, with 33.8 months in stage I and II patients [26]. Results are less promising after pleurectomy decortication (P/D) as patients receive a reduced total radiation dose given the presence of intact lung [27].

\section{Novel Therapies}

The specific biology of mesothelioma is still poorly understood. Multiple strategies are currently under investigation with a goal to improve understanding of this disease, patient survival, and treatment response. At the time of writing this review, the national clinical trials database (ClinicalTrials.gov) lists a total of 70 active and recruiting clinical trials designed to examine the effective of new therapies and treatment directions [28].

\subsection{Local Therapy}

In addition to the standardization of surgical technique and approach, additional therapies are under investigation which show promise in the operating room.

Friedberg and colleagues describe a technique of using photodynamic therapy (PDT) at the time of surgery [29]. Patients receive a photosensitizing compound that causes local cytotoxic effects when activated by light of a particular frequency. The compound is administered to the patient preoperatively as a systemic intravenous infusion and after performing a pleurectomy/decortication, the pleural cavity is illuminated by laser light. Dilute intralipid is used as a diffracting medium, which permits a diffusion of the light throughout the chest cavity. To ensure standardized light delivery, light sensors are placed in the chest at pre-defined locations prior to therapy to ensure consistent and homogenous delivery. Initial results are promising. In 2012, the group reported their experience after treating 38 patients using these techniques. All pa- 
tients in this study underwent radical pleurectomy and intraoperative PDT, with a preoperative Stage III or IV disease in $97 \%$ of patients and $18 \%$ with nonepithelial histology. After stratifying by histology, median survival was 41.2 months in the epithelioid group and 6.8 months in the non-epithelioid group [30].

Similar to treatments attempted in the peritoneal cavity, intracavitary chemotherapy at the time of surgery has been described. The agent used in this setting is either cisplatin or carboplatin, and is delivered above body temperature. Potential advantages of this technique are the ability to deliver higher concentrations of active drug, with the possibility of less systemic effects due to local delivery. There are several groups with experience who have advanced this technique over the past several decades and continue to investigate its use [31,32]. Survival advantages have been seen even in advanced disease with overall survival reported at up to 35 months in selected groups [33]. Ongoing studies are investigating the pharmacodynamics of intracavitary chemotherapy, systemic absorption, and the role of hyperthermia.

\subsection{Systemic Therapy}

\subsubsection{Immunotherapy}

Immunotherapy shows great promise in the treatment of MPM. Mesothelin is a cell-surface glycoprotein, which is strongly expressed by mesothelioma cells. As such, it makes an attractive target for immune therapies, which include monoclonal antibodies, immunotoxins, vaccines, and genetically engineered T-cells [34].

SSP1 is a high-affinity antimesothelin mouse antibody conjugated to a Pseudomonas exotoxin. Initial trials used SSP1 both alone and in combination with other therapies and showed at least stable disease with partial response in many. Trials are ongoing with this agent, which show some promise [35]. One of the challenges of immunotherapy is the fact that SSP1 itself is immunogenic, and host response may limit drug delivery to the tumor. Another trial is investigating the pretreatment of patients with immunomodulators prior to SSP1 therapy to blunt the host immune response to the immunotoxin.

Other investigational agents, directed against mesothelin, that show promise include the monoclonal antibody MORAb-009 and the antibody-drug conjugates MDX1382 and BAY 94-9343.

Disease specificity is a challenge shared by all of the immunotherapy agents. Mesothelin is a normal protein and is also expressed in low levels on normal mesothelial cells, which leads to so-called "on-target, off-tumor" effects. This may explain one of the side effects of pleuritis seen during treatment with these investigational agents. Further exploration of the biology of mesothelioma will hopefully yield new insights into novel targets that may be more disease specific.

\subsubsection{Molecular Targeted Therapy}

Molecular targeted therapy is a rapidly growing area of cancer researchas we understand more about the biologic pathways of tumorigenesis. As pathways are better understood, various mutations are identified. The key to development of a targeted therapy is the identification of a "driver mutation" or a key genetic mutation in the pathway that leads to the formation of a tumor. An example of this is the identification of the EML4-ALK fusion protein and the use of the ALK inhibitor, crizotinib, in non-small cell lung cancer [36]. Unfortunately, there are no mesothelioma specific driver mutations currently described although work is ongoing. Thus far, it appears that mesothelioma occurs largely due to loss of tumor suppressor genes rather than de-novo mutation and oncogene formation, and as such, "druggable" targets are elusive.

Despite this, a number of targeted agents have been tried empirically in mesothelioma patients. In particular, epidermal growth factor receptor (EGRF) targets and vascular endothelial growth factor (VEGF) targets were trialed, although results have been mixed [37].

\section{Conclusion}

Mesothelioma is a rare tumor but an important clinical challenge. There are several exciting developments. However, in order to ensure continued progress, it is important to maintain the integrity of our clinical trials with standardized nomenclature, adherence to guidelines, and appropriate patient selection. Trimodality therapy will likely continue to be the preferred practice in centers with surgical experience; however, novel therapies in today's era of customized medicine show great promise. The best outcomes will be assured by tailoring a treatment plan specifically to each patient situation as it presents.

\section{REFERENCES}

[1] M. J. Teta, P. J. Mink, E. Lau, B. K. Sceurman and E. D. Foster, "US Mesothelioma Patterns 1973-2002: Indicators of Change and Insights into Background Rates," European Journal of Cancer Prevention, Vol. 17, No. 6, 2008, pp. 525-534.

http://dx.doi.org/10.1097/CEJ.0b013e3282f0c0a2

[2] R. T. Lin, K. Takahashi, A. Karjalainen, et al., "Ecological Association between Asbestos-Related Diseases and Historical Asbestos Consumption: An International Analysis,” Lancet, Vol. 369, No. 9564, 2007, pp. 844-849. http://dx.doi.org/10.1016/S0140-6736(07)60412-7

[3] A. Linton, J. Vardy, S. Clarke and N. van Zandwijk, “The Ticking Time-Bomb of Asbestos: Its Insidious Role in the Development of Malignant Mesothelioma," Critical Reviews in Oncology/Hematology, Vol. 84, No. 2, 2012, pp. 200-201.

http://dx.doi.org/10.1016/j.critrevonc.2012.03.001 
[4] N. J. Olsen, P. J. Franklin, A. Reid, et al., "Increasing Incidence of Malignant Mesothelioma after Exposure to Asbestos During Home Maintenance and Renovation,” Medical Journal of Australia, Vol. 195, No. 5, 2011, pp. 271-274. http://dx.doi.org/10.5694/mja11.10125

[5] D. W. Henderson, G. Reid, S. C. Kao, N. van Zandwijk and S. Klebe, "Challenges and Controversies in the Diagnosis of Mesothelioma: Part 1. Cytology-Only Diagnosis, Biopsies, Immunohistochemistry, Discrimination between Mesothelioma and Reactive Mesothelial Hyperplasia, and Biomarkers,” Journal of Clinical Pathology, Vol. 66, No. 10, 2013, pp. 847-853.

http://dx.doi.org/10.1136/jclinpath-2012-201303

[6] D. Curran, T. Sahmoud, P. Therasse, et al., "Prognostic Factors in Patients with Pleural Mesothelioma: The European Organization for Research and Treatment of Cancer Experience,” Journal of Clinical Oncology, Vol. 16, No. 1, 1998, pp. 145-152.

[7] J. G. Edwards, K. R. Abrams, J. N. Leverment, et al., "Prognostic Factors for Malignant Mesothelioma in 142 Patients: Validation of CALGB and EORTC Prognostic Scoring Systems,” Thorax, Vol. 55, No. 9, 2000, pp. 731735. http://dx.doi.org/10.1136/thorax.55.9.731

[8] S. M. Mikulski, J. J. Costanzi, N. J. Vogelzang, et al., "Phase II Trial of a Single Weekly Intravenous Dose of Ranpirnase in Patients with Unresectable Malignant Mesothelioma,” Journal of Clinical Oncology, Vol. 20, No. 1, 2002, pp. 274-281.

http://dx.doi.org/10.1200/JCO.20.1.274

[9] N. van Zandwijk, G. Reid, A. Linton and S. Kao, "Radical Surgery for Malignant Pleural Mesothelioma: Have We Identified the Appropriate Selection Tools?” Annals of Cardiothoracic Surgery, Vol. 1, No. 4, 2012, pp. 481486.

[10] V. Rusch, E. H. Baldini, R. Bueno, et al., "The Role of Surgical Cytoreduction in the Treatment of Malignant Pleural Mesothelioma: Meeting Summary of the International Mesothelioma Interest Group Congress, September 11-14, 2012, Boston, Mass,” Journal of Thoracic and Cardiovascular Surgery, Vol. 145, No. 4, 2013, pp. 909910. http://dx.doi.org/10.1016/j.jtcvs.2013.01.039

[11] J. M. Thomas and A. I. Musani, "Malignant Pleural Effusions: A Review,” Clinics in Chest Medicine, Vol. 34, No. 3, 2013, pp. 459-471. http://dx.doi.org/10.1016/j.ccm.2013.05.004

[12] A. Levy, A. Assouline, S. Rivera, C. Chargari and P. Tai, "Role of Conservative (Palliative) Care-Only in the Management of Advanced Malignant Pleural Mesothelioma," Anticancer Research, Vol. 32, No. 9, 2012, pp. 40254027.

[13] N. J. Vogelzang, J. J. Rusthoven, J. Symanowski, et al., "Phase III Study of Pemetrexed in Combination with Cisplatin versus Cisplatin Alone in Patients with Malignant Pleural Mesothelioma,” Journal of Clinical Oncology, Vol. 21, No. 14, 2003, pp. 2636-2644. http://dx.doi.org/10.1200/JCO.2003.11.136

[14] A. Scherpereel, P. Astoul, P. Baas, et al., "Guidelines of the European Respiratory Society and the European Society of Thoracic Surgeons for the Management of Ma- lignant Pleural Mesothelioma," European Respiratory Journal, Vol. 35, No. 3, 2010, pp. 479-495. http://dx.doi.org/10.1183/09031936.00063109

[15] National Cancer Comprehensive Network, "NCCN Clinical Practice Guidelines in Oncology, Malignant Pleural Mesothelioma, v 1.2014,” 2013.

http://www.nccn.org/professionals/physician_gls/f_guidel ines.asp

[16] British Thoracic Society Standards of Care Committee, "BTS Statement on Malignant Mesothelioma in the UK, 2007,” Thorax, Vol. 62, Suppl. 2, 2007, pp. ii1-ii19.

[17] R. A. Stahel, W. Weder, Y. Lievens, et al., "Malignant Pleural Mesothelioma: ESMO Clinical Practice Guidelines for Diagnosis, Treatment and Follow-Up,” Annals of Oncology, Vol. 21, Suppl. 5, 2010. pp. v126-v128. http://dx.doi.org/10.1093/annonc/mdq173

[18] G. L. Ceresoli, P. A. Zucali, M. Mencoboni, et al., "Phase II Study of Pemetrexed plus Carboplatin in Malignant Pleural Mesothelioma,” Journal of Clinical Oncology, Vol. 24, No. 9, 2006, pp. 1443-1448. http://dx.doi.org/10.1200/JCO.2005.04.3190

[19] M. F. Muers, R. J. Stephens, P. Fisher, et al., “Active Symptom Control with or without Chemotherapy in the Treatment of Patients with Malignant Pleural Mesothelioma (MS01): A Multicentre Randomised Trial,” Lancet, Vol. 371, No. 9625, 2008, pp. 1685-1694.

http://dx.doi.org/10.1016/S0140-6736(08)60727-8

[20] E. A. Eisenhauer, W. K. Evans, N. Murray, et al., "New Response Evaluation Criteria in Solid Tumours: Revised RECIST Guideline (Version 1.1),” European Journal of Cancer, Vol. 45, No. 2, 2009, pp. 228-247. http://dx.doi.org/10.1016/j.ejca.2008.10.026

[21] A. S. Tsao, L. Garland, M. Redman, et al., “A Practical Guide of the Southwest Oncology Group to Measure Malignant Pleural Mesothelioma Tumors by RECIST and Modified RECIST Criteria,” Journal of Thoracic Oncology, Vol. 6, No. 3, 2011, pp. 598-560. http://dx.doi.org/10.1097/JTO.0b013e318208c83d

[22] E. G. Butchart, T. Ashcroft, W. C. Barnsley and M. P. Holden, "Pleuropneumonectomy in the Management of Diffuse Malignant Mesothelioma of the Pleura. Experience with 29 Patients,” Thorax, Vol. 31, No. 1, 1976, pp. 15-24. http://dx.doi.org/10.1136/thx.31.1.15

[23] D. Rice, "Standardizing Surgical Treatment in Malignant Pleural Mesothelioma," Annals of Cardiothoracic Surgery, Vol. 1, No. 4, 2012, pp. 497-501.

[24] P. E. van Schil, P. Baas, R. Gaafar, et al., "Trimodality Therapy for Malignant Pleural Mesothelioma: Results from an EORTC Phase II Multicentre Trial," European Respiratory Journal, Vol. 36, No. 6, 2010, pp. 13621369. http://dx.doi.org/10.1183/09031936.00039510

[25] T. Treasure, L. Lang-Lazdunski, D. Waller, et al., "ExtraPleural Pneumonectomy versus No Extra-Pleural Pneumonectomy for Patients with Malignant Pleural Mesothelioma: Clinical Outcomes of the Mesothelioma and Radical Surgery (MARS) Randomised Feasibility Study,” Lancet Oncology, Vol. 12, No. 8, 2011, pp. 763-772. http://dx.doi.org/10.1016/S1470-2045(11)70149-8

[26] V. W. Rusch, K. Rosenzweig, E. Venkatraman, et al., “A 
Phase II Trial of Surgical Resection and Adjuvant HighDose Hemithoracic Radiation for Malignant Pleural Mesothelioma," Journal of Thoracic and Cardiovascular Surgery, Vol. 122, No. 4, 2001, pp. 788-795. http://dx.doi.org/10.1067/mtc.2001.116560

[27] V. Gupta, L. M. Krug, B. Laser, et al., "Patterns of Local and Nodal Failure in Malignant Pleural Mesothelioma after Extrapleural Pneumonectomy and Photon-Electron Radiotherapy,” Journal of Thoracic Oncology, Vol. 4, No. 6, 2009, pp. 746-750. http://dx.doi.org/10.1097/JTO.0b013e3181a5292c

[28] ClinicalTrials.gov, 2013. http://clinicaltrials.gov/ct2/results?term=mesothelioma

[29] J. S. Friedberg, "Radical Pleurectomy and Photodynamic Therapy for Malignant Pleural Mesothelioma,” Annals of Cardiothoracic Surgery, Vol. 1, No. 4, 2012, pp. 472480.

[30] J. S. Friedberg, M. J. Culligan, R. Mick, et al., "Radical Pleurectomy and Intraoperative Photodynamic Therapy for Malignant Pleural Mesothelioma," Annals of Thoracic Surgery, Vol. 93, No. 5, 2012, pp. 1658-1665. http://dx.doi.org/10.1016/j.athoracsur.2012.02.009

[31] V. Rusch, L. Saltz, E. Venkatraman, et al., “A Phase II Trial of Pleurectomy/Decortication Followed by Intrapleural and Systemic Chemotherapy for Malignant Pleural Mesothelioma," Journal of Clinical Oncology, Vol. 12, No. 6, 1994, pp. 1156-1163.
[32] P. H. Sugarbaker, O. A. Stuart and C. Eger, "Pharmacokinetics of Hyperthermic Intrathoracic Chemotherapy Following Pleurectomy and Decortication," Gastroenterology Research and Practice, Vol. 2012, 2012, Article ID: 471205. http://dx.doi.org/10.1155/2012/471205

[33] W. Weder and I. Opitz, "Multimodality Therapy for Malignant Pleural Mesothelioma,” Annals of Cardiothoracic Surgery, Vol. 1, No. 4, 2012, pp. 502-507.

[34] J. Villena-Vargas and P. S. Adusumilli, "MesothelinTargeted Immunotherapies for Malignant Pleural Mesothelioma," Annals of Cardiothoracic Surgery, Vol. 1, No. 4, 2012, pp. 466-471.

[35] R. J. Kelly, E. Sharon, I. Pastan and R. Hassan, "Mesothelin-Targeted Agents in Clinical Trials and in Preclinical Development,” Molecular Cancer Therapeutics, Vol. 11, No. 3, 2012, pp. 517-525. http://dx.doi.org/10.1158/1535-7163.MCT-11-0454

[36] E. L. Kwak, Y. J. Bang, D. R. Camidge, et al., “Anaplastic Lymphoma Kinase Inhibition in Non-Small-Cell Lung Cancer," New England Journal of Medicine, Vol. 363, No. 18, 2010, pp. 1693-1703. http://dx.doi.org/10.1056/NEJMoa1006448

[37] A. K. Nowak, "Chemotherapy for Malignant Pleural Mesothelioma: A Review of Current Management and a Look to the Future," Annals of Cardiothoracic Surgery, Vol. 1, No. 4, 2012, pp. 508-515. 